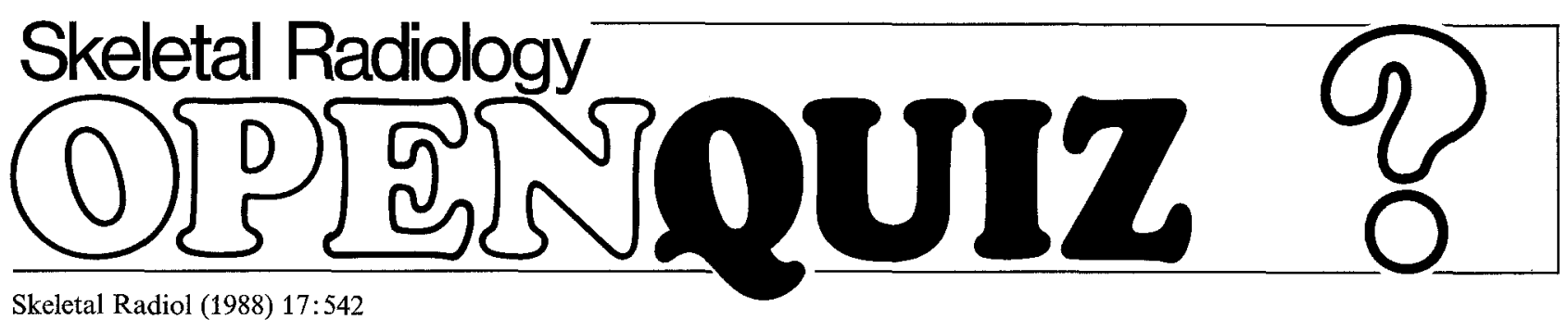

Answers must be received by Dr. Jacobson no later than December 9, 1988. The solution will be published in Volume 18 , Number 1, 1989. Individuals from the department of practice from which the case originated will not patricipate in the quiz. Thus, cases chosen for the quiz will not come from any of the cases presented at the closed meetings of the Society.

\title{
Case report 511
}

\author{
R.J. Hernandez, M.D. ${ }^{1}$, J.T. Headington, M.D. ${ }^{2}$, R.A. Kaufman, M.D. ${ }^{3}$, and W. Martel, M.D. ${ }^{1}$ \\ Departments of ${ }^{1}$ Radiology and ${ }^{2}$ Pathology, The University of Michigan Hospitals, Ann Arbor, Michigan, \\ ${ }^{3}$ Department of Radiology and Pediatrics, Children's Hospital Medical Center and the \\ University of Cincinnati College of Medicine, Cincinnati, Ohio, USA
}

\section{Radiological studies}
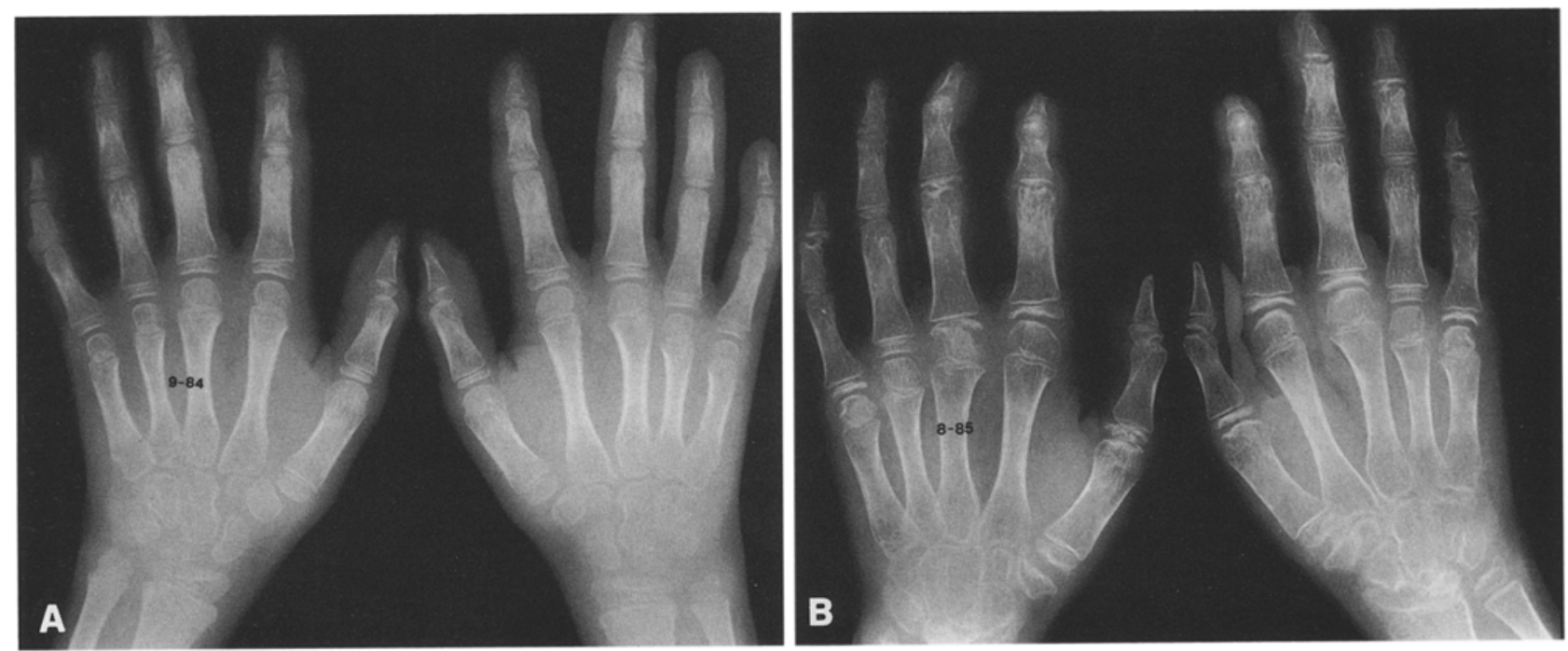

Fig. 1. A Frontal radiograph of the hands at the time of appearance of the skin nodules. Besides the soft tissue nodules no radiographic abnormality was noted. The carpal size is normal. B Radiograph of the hands obtained one year later. Observe the marked destructive changes involving the carpus, metacarpophalangeal joints and proximal and distal interphalangeal joints

\section{Clinical information}

An eight-year-old white male child, who was well until six months prior to being evaluated at the University of Michigan, developed multiple skin nodules over his right elbow, knees, dorsum of the hands and fingertips. The skin lesions were papulo-nodular and reddish. Approximately two to three months after the appearance of the nodules, he noted pain and stiffness in his wrists and knees. He also developed Raynaud's phenomena of the fingers of the left hand. Radiographs of the hands demonstrated soft tissue swelling, but no

Address reprint requests to: Ramiro J. Hernandez, M.D., Section of Pediatric Radiology, C.S. Mott Children's Hospital, 1500 E. Medical Center Drive, University of Michigan Hospitals, Ann Arbor, MI 48109-0252, USA evidence of bony or cartilaginous destruction. The carpal size was normal (Fig. $1 \mathrm{~A}$ ).

One year later the patient developed severe bone and cartilage destruction bilaterally which involved the carpus, the metacarpophalangeal joints, and proximal and distal interphalangeal joints. In addition to growth disturbances, joint space narrowing and erosive changes developed (Fig. $1 \mathrm{~B}$ ). Similar changes were present in the elbows and feet. Ophthalmological examination was normal. The rheumatoid factor and lyme serology were negative. Synovial biopsy of the left wrist, performed at this time, demonstrated a slight granulation tissue-like response. A slight increase in blood vessels and a few extra lymphocytes and other mononuclear cells in the subserosal zone were noted; these changes were minimal. No evidence of rheumatoid arthritis was present. Biopsy of one of the skin nodules was performed. 